\title{
Studies in the synthesis of 2,4,6-trichloro-1,3,5-triazine derivatives
}

\author{
Vineeta Khatri $^{a}$, Vineeta Sareen ${ }^{a}$, Urmila Garg ${ }^{a}$, Poonam Taneja ${ }^{a}$ and Kanti Sharma ${ }^{b^{*}}$ \\ "Department of Chemistry, University of Rajasthan, Jaipur-302 004, India \\ ${ }^{b}$ Department of Chemistry, R. L. Saharia Government P. G. College, Kaladera, Jaipur-303 801, India \\ Munuscript received 25 February 2002, revised 7 August 2002. accepted 6 September 2002
}

\begin{abstract}
2,4,6-Trichloro-1,3,5-triazine derivatives are reacted selectively (one or more at a time) with nucleophilic reagents ( $p$-fluoroaniline, $p$-toluidine and different substituted amines); even the deactivated mono- and disubstituted and sometimes trisubstituted products of 2,4,6-trichloro-1,3,5-triazine show high reactivity towards substitution. The mechanism of this reaction has been discussed.
\end{abstract}

$s$-Triazine derivatives possess various biological activities'. In order to obtain some new compounds having biological activities, three chlorine atoms of 2,4,6-trichloro-1,3,5-triazine have been replaced by $p$-fluoroaniline, $p$-toluidine and different substituted amines. 2,4-Dichloro-6-(4fluoroanilino)-1,3,5-triazine (2) has been prepared by treating cyanuric chloride with $p$-fluoroaniline (1). The mixture was kept alkaline during the reaction with sodium hydroxide and the contents were poured on ice and acidified with dil. $\mathrm{HCl}$ to furnish the product $\mathbf{2}$ in quantitative yield.

The second chlorine atom of 2 has been replaced by $p$ toluidine to give 2-chloro-4-(4-fluoroanilino)-6-(4-methylanilino)-1,3,5-triazine (3) as the sole product. The third chlorine atom of $\mathbf{3}$ has been replaced by different aromatic amines to produce 2-alkyl/arylamino-4-(fluoroanilino)-6(4-methylanilino)-1,3,5-triazines (4).

\section{Results and discussion}

2,4,6-Trichloro-1,3,5-triazine derivatives (cyanuric chloride) reacts selectively with nucleophilic reagents ${ }^{2,3}$. Cyanuric chloride is a weak base. If one of its chlorines is re-placed by NHR, OR or SR, the basicity is increased beause of the electron-releasing effect of these groups substituted at $\alpha$-positions of the ring nitrogen atoms. The substitution is catalyzed by acid $^{4}$. To prevent possible acid catalysis in the substitution of the chlorine atom of 2,4,6-trichloro-1,3,5-triazine by $\mathrm{OH}, \mathrm{OCH}_{3}$ or $\mathrm{OC}_{2} \mathrm{H}_{5}$ to give a hydroxy, methoxy or ethoxy dichloro-s-triazine, the reaction is best carried out in the presence of an acid binding medium preferably sodium bicarbonate. Substitution by the elec-trondonating group adjacent to ring nitrogen atom is in the following decreasing sequence : $\mathrm{OC}_{6} \mathrm{H}_{5}>\mathrm{OCH}_{3}>\mathrm{OCH}_{2} \mathrm{H}_{5}>$ $\mathrm{NH}_{2}>\mathrm{NHCH}_{3}>\mathrm{NHC}_{2} \mathrm{H}_{5}>\mathrm{NC}\left(\mathrm{CH}_{3}\right)_{2}>\mathrm{OH}$. The reactivity of the chlorine atom in the 2,4-disubstituted-6-chloro1,3,5-triazines behave similarly for the substitution reaction.

\section{Experimental}

Purity of all the compounds was checked by TLC (silica gel G) using iodine vapor as the detecting agent. M.ps. were determined in open capillary tubes using a Gallen - Kamp apparatus and are uncorrected. IR spectra $(\mathrm{KBr})$ were recorded on a Perkin-Elmer 577 spectrophotometer, mass spectra on Kratos MS-30 and MS-50 spectrometers operat-

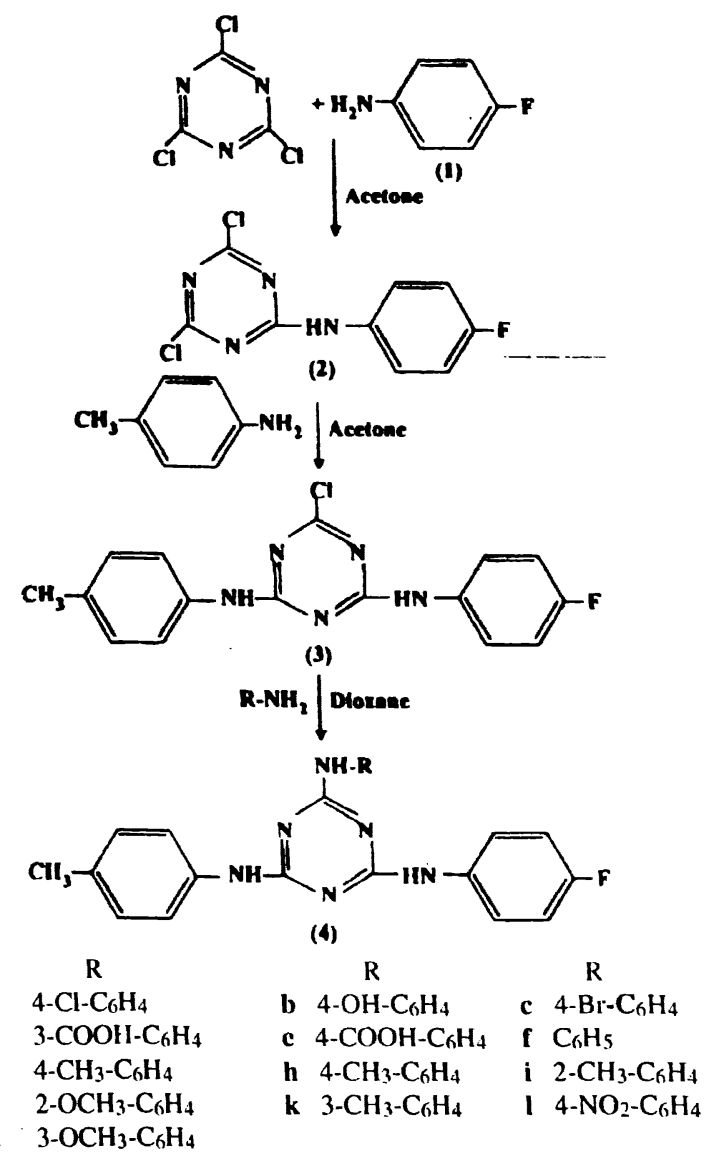

Scheme 1 
ing at an ionization potential of $70 \mathrm{eV}$ and PMR spectra on a Jeol FX 9()Q apparatus (89.99 MHz) with TMS as the internal standard.

2,4-Dichloro-6-(4-fluoroanilino)-1,3,5-triazine (2) : To 2,4,6-trichloro-1.3,5-triazine ( $18.4 \mathrm{~g}, 0.1 \mathrm{~mol}$ ) dissolved in acetone $(100 \mathrm{ml})$ cooled at $0^{\circ}, p$-fluoroaniline $(11.1 \mathrm{~g}, 0.1$ $\mathrm{mol}$ ) dissolved in acetone $(100 \mathrm{ml})$ was added with stirring at ()$-5^{\circ}$. followed by dropwise addition of $\mathrm{NaOH}(4.0 \mathrm{~g} .0 .1$ mol) in water $(50 \mathrm{ml})$. Contents were stirred for $3 \mathrm{~h}$, then poured into ice-water and acidified with dil. $\mathrm{HCl}$. The resulting solid was washed with acetone, dried and crystallized from ethanol. (79\%), m.p. 186 (Found : C. 41.55; H, 1.88; N, 21.56. $\mathrm{C}_{9} \mathrm{H}_{5} \mathrm{Cl}_{2} \mathrm{FN}_{4}$ requires: $\mathrm{C}, 41.69: \mathrm{H}, 1.93 ; \mathrm{N}$, $21.62 \%) ; v_{\text {mix }} 3130 \mathrm{~cm}^{-1}(\mathrm{NH}) ; \delta 9.85(1 \mathrm{H}, \mathrm{s}, \mathrm{NH}), 8.5-8.1$ $(4 \mathrm{H}, \mathrm{m} . \mathrm{ArH}): \mathrm{m} / \approx \mathrm{M}^{+}, 259$.

2-Chloro-7-(4-fluorocanilino)-6-(4-methylanilino)-1,3,5tria-inc (3) : A solution of 2 (25.9 g. $0.1 \mathrm{~mol})$ dissolved in acetone $(100 \mathrm{ml})$ was added to $p$-toluidine $(10.7 \mathrm{~g} .0 .1 \mathrm{~mol})$ in acetone $(100 \mathrm{ml})$ slowly with stirring followed by the addition of $\mathrm{NaOH}(4.0 \mathrm{~g}, 0.1 \mathrm{~mol})$ in water $(50 \mathrm{ml})$. The reaction mixture was stirred for $3 \mathrm{~h}$ at $30-40^{\circ}$. then poured in ice-water and acidified with dil. $\mathrm{HCl}$. The resulting solid was washed with acetone, dried and crystallized from ethanol, (75\%), m.p. 254 (Found: C, 58.31: H, 4.01; N, 21.28. $\mathrm{C}_{16} \mathrm{H}_{13} \mathrm{CIFN}_{5}$ requires : C. 58.27: $\mathrm{H}, 3.94 ; \mathrm{N}$,
$21.24 \%) ; v_{\operatorname{mix}} 3120 \mathrm{~cm}^{-1}(\mathrm{NH}) ; \delta 8.7(2 \mathrm{H}, \mathrm{s}, \mathrm{NH}), 8.4-7.8$ $(8 \mathrm{H}, \mathrm{m} . \mathrm{ArH}), 2.21\left(3 \mathrm{H}, \mathrm{s}, \mathrm{CH}_{3}\right) ; \mathrm{m} / z \mathrm{M}^{+}, 329.5$.

2-(4'-Chlorophenyl)amino-4-(4-fluoroanilino)-6-(4-methylanilino)-1,3,5-triazine (4a) : To a solution of $3(0.01$ $\mathrm{mol})$ in dioxane $(50 \mathrm{ml})$ were added $p$-chloroaniline $(0.01$ $\mathrm{ml})$ and $\mathrm{NaOH}(0.01 \mathrm{~mol})$ in water $(10 \mathrm{ml})$ and the mixture was refluxed at $85-90^{\circ}$ for $2 \mathrm{~h}$. It was poured onto ice and the resulting solid was dried and crystallized from ethanol, $(68 \%)$, m.p. $205^{\circ}$ (Found : C, 62.82; H. 4.24; N, 19.92. $\mathrm{C}_{22} \mathrm{H}_{18} \mathrm{ClFN}_{6}$ requires : C, 62.78; H, 4.28; N, 19.97\%); $v_{\text {mix }}$ $3100 \mathrm{~cm}^{-1}(\mathrm{NH}) ; \delta 8.1(3 \mathrm{H}, \mathrm{s}, \mathrm{NH}), 8.0-7.5(12 \mathrm{H}, \mathrm{m}$, ArH), 2.0 (3H, s, $\left.\mathrm{CH}_{3}\right) ; m / z \mathrm{M}^{+}$. 420.5. Compounds (4b-m) were similarly prepared (yields 53-66\%) : 4b, m.p. $300^{\circ} \mathrm{d}$; c, $196^{\circ} ; \mathbf{d}, 182^{\circ} ; \mathbf{e}, 292^{\circ} ; \mathbf{f}, 234^{\circ} ; \mathbf{g}, 262 ; \mathbf{h}, 250^{\circ} ; \mathbf{i}, 300^{\circ} ; \mathbf{j}$. $266^{\circ} ; \mathbf{k}, 277^{\circ} ; 1,172^{\circ} ; \mathbf{m}, 284^{\circ}$.

\section{References}

1. P. S. Desai and K. R. Desai. J. Indian Chem. Sor., 1994. 77. 155: K. Rolf. R. H. Jochem, L. Stefan. V. Katharina and K. Kristian. Chem. Abstr. 1999, 131, 243289; R. Hans Jochem, L. Stefan. V. Katharina, D. Markus. D. M. Wilhelm and G. Toshio, Chem. Abstr., 1999. 131. 214303: K. M. Joseph. D. W. Ludovici. R. W. Kavash, J. Heeres and A. J. Janssen, Chem. Abstr., 1999, 131. 243290

2. P. Klason, J. Pract: Chem. 1986. 2. 152.

3. M. Goi, Z. Koshida and K. Konishi, Chem. Abstr.. 1963, 59. 5165.

4. C. K. Banks, O. M. Gruhzit. J. Controulis and E. W. Tillitson, J. Am. Chem. Soc.. 1944, 66. 1771. 